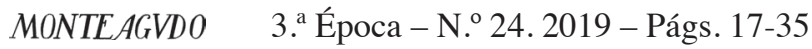

\title{
José María Merino: teoría y PRÁCTICA del MiCrorRelato
}

\author{
ÁNGEL BASANTA \\ Presidente de la \\ Asociación Española de Críticos Literarios
}

\section{RESUMEN:}

El microrrelato ha alcanzado un extraordinario auge en las últimas décadas. Se define por su acusada brevedad y su intensa narratividad, su extrema concentración y economía expresiva sustentadas en la elipsis y el arte de sugerir. Aunque ha habido microrrelatos desde las primeras manifestaciones de la literatura, este cuarto género narrativo nace como tal a partir del Romanticismo y, sobre todo, en el Modernismo, alcanza su pleno desarrollo a lo largo del siglo XX, a partir de J. R. Jiménez y R. Gómez de la Serna, en España, y, más aún, en Hispanoamérica, con maestros como Borges, A. Monterroso y J. Cortázar; y se consolida como el cuarto género narrativo a finales del XX y comienzos del XXI. José $\mathrm{M}^{\mathrm{a}}$ Merino es uno de los escritores españoles que más y mejor ha contribuido a la construcción de la teoría del microrrelato y está considerado como uno de los maestros indiscutibles en la creación de minificciones representativas de esta modalidad narrativa. Reunió sus microrrelatos por primera vez en La glorieta de los fugitivos. Minificción completa (2007). A ellos hay que añadir los intercalados después entre los cuentos de El libro de las horas contadas (2011) y los agrupados en la tercera parte de La trama oculta (cuentos de los dos lados con una silva mínima) (2014).

\section{PALABRAS CLAVE:}

Cuento, hipotexto, intertextualidad, microrrelato, minicuento, minificción, narratividad, relato.

\begin{abstract}
:
The short short-story is flourishing in recent decades. It is defined by its acute brevity and its intense narrativity, its concentrated form and expressive economy underpinned by its elliptical and suggestive nature. Although there have been instances of short short-stories since the beginnings of the literary form, this narrative genre begins to take shapre in the Romantic and Modernist periods, and develops fully in the twentieth century, in the writings of J. R. Jiménez and R. Gómez de la Serna in Spain and, in Latin America, in those of Borges, A. Monterroso y J. Cortázar. It becomes consolidated as the fourth narrative genre at the end of the twentieth and the beginning of the twenty-first centuries. José María Merino is one of the Spanish writers who has done most to contribute to the development of the theory of the short short-story and is widely considered one of the best creators of the mini-fictions representative of this narrative mode. His first collection of short short-stories is La glorieta de los fugitivos. Minificción completa (2007), to which he has since added others to be found amongst the short stories of El libro de las horas contadas (2011) and those grouped in the third part of La trama oculta (cuentos de los dos lados con una silva mínima) (2014).
\end{abstract}

\section{KEYWORDS:}

Short story, hypotext, intertextuality, short shortstory, «mini-fiction», narrativity. 
José María Merino es uno de los escritores españoles de nuestro tiempo que mejores frutos ha obtenido de su maestría en el dominio de todas las formas narrativas en prosa: la novela, la novela corta, el cuento y el microrrelato. En Merino se da, en el más alto grado, la peculiaridad de combinar la especulación teórica y la realización práctica en estos cuatro géneros narrativos. Pues con frecuencia este autor leonés nacido en La Coruña ha reflexionado con lucidez sobre diferentes aspectos de teoría narrativa y sobre novelas escritas por otros, como Pushkin, Tolstoi, Stevenson, Conrad y H. Hesse, entre los extranjeros, Galdós, Max Aub, Torrente Ballester y Delibes, entre los españoles. Pero es en las modalidades de la narrativa breve donde Merino se ha prodigado con más empeño en el estudio del cuento, tanto en sus reflexiones teóricas sobre los componentes del mismo como en la confección de antologías de cuentos y en el análisis de los escritos por otros a lo largo de la historia de la literatura, desde la colección medieval Calila e Dimna, de la que ha hecho una primorosa edición ${ }^{1}$, hasta Medardo Fraile, pasando por Hoffmann, Clarín y Maupassant, entre otros. Y la misma dedicación simultánea se aprecia en el campo del microrrelato, con enjundiosas consideraciones teóricas sobre su naturaleza y una fecunda práctica del mismo.

\section{Brevísima introducción al microrrelato}

El microrrelato es la narración breve de una historia escrita en prosa y estructurada con extrema concentración, tensión e intensidad. Entre sus características fundamentales, que lo distinguen de otros géneros cercanos, como el cuento, el aforismo y el poema en prosa, destacan la brevedad y la narratividad, además de la máxima economía expresiva. Aunque hubo microrrelatos desde los tiempos de Sherezade, el género tiene sus orígenes a partir del Romanticismo, sobre todo en el Modernismo, con Rubén Darío a la cabeza, alcanza su pleno desarrollo a lo largo del siglo XX, en España y, más aún, en Hispanoamérica, con maestros como Borges, Arreola, Monterroso y Cortázar, y se consolida como tal a finales del XX y comienzos del XXI. En la historia literaria española, como explica Irene Andres-Suárez (2012: 26), «el microrrelato es el resultado de la evolución de dos géneros literarios distintos: el poema en prosa y el cuento clásico. Es decir, los escritores de principios del siglo XX llegaron a este hallazgo formal y estético a través de dos vías: a) mediante la disminución de la descripción y el aumento progresivo de la narratividad del poema en prosa (Juan Ramón Jiménez), y b) mediante la compresión textual y pulimento del cuento clásico (Ramón Gómez de la Serna)»,

\footnotetext{
${ }^{1}$ Calila y Dimna, edición modernizada por José Ma Merino, Madrid, Páginas de Espuma, 2016.
} 
A partir de aquellos orígenes el microrrelato español pasa por García Lorca y encuentra manifestaciones importantes en la posguerra con los postistas y sus continuadores, y en algunas obras de Ana María Matute, Max Aub, Francisco Ayala e Ignacio Aldecoa; llega a su consolidación como género a finales del siglo XX con textos, algunos ya clásicos, de Luis Mateo Díez, Javier Tomeo, Jiménez Lozano, Juan José Millás e Hipólito G. Navarro, entre otros; y entra en el siglo XXI consagrado como «el cuarto género narrativo» por obra de cultivadores de reconocido prestigio como José María Merino, Juan Pedro Aparicio, Luciano G. Egido, Ángel Olgoso, Ángel Zapata y Andrés Neuman, además de los citados antes y una larga nómina de autores más jóvenes atraídos por esta nueva modalidad narrativa.

En esta constitución del microrrelato como nuevo género literario han influido tanto la publicación de narraciones hiperbreves por autores consagrados, la irrupción de jóvenes especializados en el cultivo de este nuevo género narrativo y el apoyo prestado por algunas editoriales como la aparición de importantes estudios teóricos que en los últimos años han contribuido a fijar las características del género y explicar su historia. De ello es buena muestra la coincidencia de dos valiosas antologías en el año 2012, a cargo de dos especialistas (autores, además, de sendas monografías sobre dicha forma narrativa): Antología del microrrelato español (1906-2011), de I. Andres-Suárez, que abarca la historia del microrrelato desde el Modernismo hasta el presente, y Mar de pirañas. Nuevas voces del microrrelato español, en la que F. Valls se centra en la actualidad del microrrelato y en sus autores más jóvenes.2

\section{Merino y su teoría del microrrelato}

Merino ha expuesto por escrito su teoría del microrrelato en varias ocasiones. En las dos primeras lo hizo por vía del ensayo teórico: «De relatos mínimos» y «El

\footnotetext{
${ }^{2}$ Estos son los datos de las monografías aludidas: Fernando Valls, Soplando vidrio y otros estudios sobre el microrrelato español, Madrid, Páginas de Espuma, 2008; e Irene Andres-Suárez, El microrrelato español. Una estética de la elipsis, Palencia, Menoscuarto, 2010; debe añadirse también la compilación de estudios realizada por Andres-Suárez y Antonio Rivas (eds.), La era de la brevedad. El microrrelato hispánico (Actas del IV Congreso Internacional de Minificción), Palencia, Menoscuarto, 2008; y el libro inaugural de David Lagmanovich, El microrrelato. Teoría e historia, Palencia, Menoscuarto, 2006. La antología de Andres-Suárez (2012) y la de Fernando Valls (2012) se citan en la bibliografía final; a ellas deben añadirse la preparada por Ángeles Encinar y Carmen Valcárcel (2011) y la anterior de David Lagmanovich (2005), también recogidas en la bibliografía final. Y como aportaciones más recientes hay que destacar el excelente artículo de Fernando Valls (2015) sobre teoría del microrrelato y el libro de Andres-Suárez (2018) dedicado al microrrelato español en catalán, gallego y vasco, también citados en la bibliografía final. En conjunto, estos estudios ofrecen una excelente información para adentrarse en el mundo del microrrelato hispánico, en sus formas y en su historia.
} 
microrrelato. Teoría e historia». Las dos siguientes constituyen muestras ejemplares de simbiosis de teoría y práctica por su integración de la exposiciones teóricas en la creación de originales microrrelatos metaliterarios en los que se reflexiona sobre su forma narrativa: «Diez cuentos brevísimos, con unas gotas de teoría» y «La glorieta miniatura (veinticinco pasos)». ${ }^{3}$

En estos trabajos Merino aborda el análisis teórico del microrrelato con inteligencia, rigor y sensatez, más el profundo conocimiento que le da la práctica del género. Así, en su primer acercamiento teórico, «De relatos mínimos» (2002), el autor empieza por delimitar el campo de estudio, destacando las denominaciones más frecuentes para nombrar el género: «microrrelatos, minificciones, ficciones súbitas, relatos hiperbreves»..., y señalando la extensión habitual de este tipo de texto literario en miniatura, «por lo general no superior a dos páginas, muy a menudo desarrollado en una sola línea». Luego se ocupa de algunas antologías pioneras de microrrelatos, ejemplifica con textos incluidos en ellas y destaca las primeras aportaciones de autores españoles, entre los que Merino se adelanta en incluir en lugar destacado al gallego Á. Cunqueiro y al catalán J. Perucho.

Consciente de que aún no se había llegado a una denominación comúnmente aceptada ni tampoco a una cabal definición del microrrelato, nuestro autor acierta en señalar como rasgos constitutivos del género «la brevedad del texto» y su «específica naturaleza narrativa», ponderando de modo especial «la tensión narrativa» y «el esfuerzo de síntesis dramática», así como también «su proteica adaptabilidad, su capacidad de asumir pequeños textos de difícil encaje en los géneros tradicionales, su aptitud para aprovechar la brevedad y cargarla de omisión y sugerencia». Transcurridos más de quince años, podemos ver ahora que los elementos constitutivos realzados por Merino son los mismos que los especialistas en el microrrelato coinciden en destacar como fundamentales en su naturaleza. Pero ya por entonces Merino se adelantaba en advertir de los mayores peligros en el cultivo del género, propiciados por la falta de canon debida a su exigua historia y por el prejuicio de que «todo vale con tal de que sea corto», lo cual puede multiplicar, al lado de textos valiosos, pobres

\footnotetext{
${ }^{3}$ He aquí las referencias bibliográficas: «De relatos mínimos», publicado por primera vez en Revista de libros, núm. 70, Madrid, octubre de 2002, y recogido en Ficción continua, Barcelona, Seix Barral, 2004, págs. 229-237; «El microrrelato. Teoría e historia», Revista de libros, núm. 129, Madrid, septiembre de 2007; «Diez cuentos brevísimos, con unas gotas de teoría», en Teresa Gómez Trueba (ed.), Mundos mínimos. El microrrelato en la literatura española contemporánea, Gijón, Cátedra Miguel Delibes-Libros del Pexe, 2007, págs. 183-192; y «La glorieta miniatura (veinticinco pasos)» contiene textos escritos para la intervención del autor en el IV Congreso Internacional de Minificción, celebrado en la Universidad de Neuchâtel en noviembre de 2006; fueron publicados en I. Andres-Suárez y A. Rivas (eds.), La era de la brevedad, cit., págs. 547-558, y después recogidos por Merino en La glorieta de los fugitivos. Minificción completa, Madrid, Páginas de Espuma, 2007, págs. 193-220.
} 
pseudocuentos llenos de «bagatela verbal» $\mathrm{y}$ «bisutería retórica», que condenarían al microrrelato a ser un «género menor» o un simple «cajón de sastre».

En el segundo trabajo citado, «El microrrelato. Teoría e historia» (2007), empieza resumiendo la milenaria historia en la creación no sistemática de cuentos brevísimos, desde los imaginarios indio, chino y egipcio hasta el siglo XX, cuando aprecia su consagración como «un género de naturaleza peculiar, diferente, propio de la modernidad». A continuación enumera los nombres que ha recibido («microcuento, minificción, microrrelato, relato instantáneo, vertiginoso, ultracorto, hiperbreve, ficción súbita, textículo»), destaca el predominio de su cultivo en el mundo de habla española y se detiene en el examen del libro de D. Lagmanovich, que Merino considera «la primera aproximación de envergadura al fenómeno» por su atención a todas las literaturas hispánicas y su relación con grandes escritores en otras lenguas. Finalmente, lo más novedoso introducido aquí por Merino en su teoría del microrrelato está en la exigencia de un lector especialmente avisado, activo y cómplice, muy preparado, más aún que el lector reclamado por el cuento literario, pues en los relatos hiperbreves la elipsis y la concentración expresiva se agudizan al máximo, por lo cual «es necesario un lector dispuesto a poner de su parte lo que la extrema síntesis del relato escamotea», es decir, los microrrelatos requieren «un lector preparado para que sean captados en toda su intensidad e ironía en el momento mismo en que transcurren».

A la vez que maduraban sus ideas acerca del género, el autor nos ofrece algunas joyas literarias en La glorieta miniatura (veinticinco pasos), en las cuales se integran, more cervantino, teoría y práctica del microrrelato en el mismo texto. Los mismos aspectos tratados en los ensayos teóricos reaparecen ahora sumergidos en la invención creadora. Para ello el autor se desdobla en su heterónimo el profesor Souto, a quien le atribuye ideas compartidas por ambos, empezando por afirmar que «La ficción fue la primera sabiduría de la humanidad» ${ }^{4}$, para llegar a establecer un mundo imaginario cifrado en la metáfora del Jardín Literario, en uno de cuyos extremos, lindando con la leyenda, la fábula, la poesía y el cuento, «se halla la Glorieta Miniatura», rodeada por «el inmenso bosque de la ficción pequeñísima» (págs. 202, 204 y 205).

También se repasan las características del género y sus procedimientos, como la exigencia de brevedad, depuración y elipsis, aunque sin llegar a extremos descalificados con humor en el titulado La podadera, que dice así:

Para el vigoroso crecimiento del cuento minúsculo es muy conveniente el arte de la poda: hay jardineros enloquecidos que sueñan con conseguir un minicuento que no precise texto, ni título. (pág. 208)

${ }^{4}$ Cito siempre por los textos reunidos en La glorieta de los fugitivos, cit., pág. 196. 
Lo mismo sucede con la imprescindible narratividad y el necesario movimiento interno en todo microrrelato, plasmados como elementos constitutivos del microtexto titulado Sobre velocidad:

¿Relatos vertiginosos, ficciones súbitas, cuentos fugitivos? De acuerdo, pero el buen microrrelato debe moverse con mucha rapidez mientras permanece inmóvil. (p. 218)

Otras características frecuentes en muchos microrrelatos, como la intertextualidad y el juego con la tradición literaria, reciben su creativo tratamiento al ponderar que «gran número de relatos hiperbreves se alimenta de materia literaria ya muy macerada por el tiempo y las relecturas» (pág. 209). Asimismo el profesor Souto resalta las infinitas posibilidades de alumbramiento de microrrelatos en repentinas floraciones que pueden dar lugar a interminables mutaciones e ilimitadas hibridaciones. Por lo cual muchos de estos textos tan breves reclaman lectores altamente cualificados, pues, como se afirma en el titulado De simbiosis (pág. 210), «Esos microrrelatos cobran la figura de una ficción, y el lector pone casi toda la sustancia. En el proceso de lectura, el minicuento segrega un peculiar fluido hipnótico, de manera que tal vez el lector está leyendo algo ya conocido que, bajo la forma de tal minificción, tiene sabor de primera lectura». Y no podía faltar en tan lúcidas reflexiones acerca del género, que el profesor Souto ha sabido integrar en la práctica de estos «veinticinco pasos», un final ejemplar con una pieza excelente que reclama un lector preparado para entender bien esa ingeniosa Historia de don Quijote en dos líneas, que luego comentaremos.

Al mismo tiempo que se dibuja la geografía literaria del microrrelato y se revisan sus características, en los veinticinco textos se repasan los nombres más frecuentes en su denominación: además del neologismo «nanocuento», adelantado en el antetexto del libro, van sucediéndose otras denominaciones como «microrrelato», «ficción pequeñísima», «cuento minúsculo», «minicuento», «relato brevísimo», «relatos hiperbreves», «relatos vertiginosos», «relatos diminutos», «relatos mínimos», «microficciones», «minificciones», «ficciones mínimas», «ficciones súbitas», «cuentos fugitivos», hasta llegar a la humorística solución en uno de los diez textos añadidos en el apéndice. Se titula Genética. Dice así:

Microrrelato se casó con Minificción y tuvieron muchos minicuentos, pero todos les salieron bobos, menos uno al que llamaron Cuentín. (pág. 225)

Y enseguida el autor de estos Diez cuentines congresistas aprovecha la ocasión para lanzar algunos dardos contra los eruditos a la violeta, sin perder el tono humorístico, en la pieza titulada Final infeliz: 
José María Merino: teoría y práctica del microrrelato

Un cuentín y una cuentina se encontraron en una mesa redonda y se escaparon juntos, pero un profesor los logró atrapar de nuevo y los devolvió a la antología. A ella la puso en la jaula de las minificciones y a él en la de los microrrelatos. Nunca más volvieron a encontrarse (pág. 227).

Entre bromas y veras, lo cierto es que Merino ha ideado una teoría del microrrelato muy aceptada entre los estudiosos, nacida de la reflexión inteligente y explicada con ingenio y brillantez, tanto en sus especulaciones teóricas como en algunas creaciones de metamicrorrelatos que ya hemos visto. En una breve introducción, bajo el rubro de «Pequeño y volátil», encontramos una prueba más de la lúcida visión meriniana de las propiedades del microrrelato: «Que sea pequeño pero que sea volátil, que desaparezca enseguida de nuestro campo de visión, pero que nos deje una intensa imagen de ese mundo paralelo, certero, hecho solo con palabras, que tiene que suscitar la narrativa verdadera» ${ }^{5}$.

Así pues, como explicaba el autor en una entrevista en 2007, un microrrelato «no es el esquema cortito de un cuento más largo. Tiene que ser en sí mismo el cuento exacto». Porque «es una quintaesencia narrativa, capaz de moverse y cambiar desde el principio hasta el fin». Y por su brevedad, concentración, movimiento y elipsis, exigidos por el arte de decir mucho en el menor espacio posible, más un permanente juego de intertextualidades, «el microrrelato deja al lector una parte importantísima del trabajo» ${ }^{6}$, para que empeñe su amplia formación con el fin de llegar a una cabal co-creación del texto. Pues «cada minificción es, en palabras de Lauro Zavala, una maquinaria textual que propone una manera de releer lúdicamente la historia de la literatura». Por ello las aportaciones de Merino han merecido el reconocimiento de los más acreditados especialistas en el microrrelato. Sirva de muestra esta afirmación de F. Valls en la cual pondera que «los lectores le debemos algunas de las contribuciones, teóricas y prácticas, más sobresalientes realizadas en nuestro país sobre narrativa brevísima». ${ }^{7}$

\footnotetext{
${ }^{5}$ José $\mathrm{M}^{\mathrm{a}}$ Merino, «Pequeño y volátil», texto introductorio a la selección de sus microrrelatos en Neus Rotger y Fernando Valls (eds.), Ciempiés. Los microrrelatos de Quimera, Barcelona, Montesinos, 2005, págs. 79-80. Tomo el texto del ya citado libro de D. Lagmanovich, pág. 262.

${ }^{6}$ Todas estas citas entrecomilladas pertenecen a respuestas de Merino en la entrevista que le hizo Winston Manrique Sabogal en Babelia, El País, Madrid, 1 de septiembre de 2007, págs. 2-3; las citas en pág. 2. La cita siguiente de Lauro Zavala se encuentra en el mismo Babelia, pág. 3.

${ }^{7}$ Fernando Valls, Soplando vidrio, cit., pág. 168.
} 


\section{3. ... y la práctica}

La incorporación de Merino al cultivo de microrrelatos es relativamente tardía, pues no se produce hasta comienzos del siglo XXI. Aunque algunos microrrelatos suyos habían aparecido ya en los años noventa del siglo anterior. Los tres primeros fueron escritos por encargo de A. Fernández Ferrer para ser incluidos en su antología La mano de la hormiga (1990) ${ }^{8}$. En aquellas creaciones confiesa Merino haber descubierto el mundo del microrrelato, fascinado por las nuevas posibilidades expresivas que dicho artefacto le ofrece, sobre todo en la conjunción experimental de máxima intensidad y mínima extensión en la misma ficción. Después escribió algunos microrrelatos más para otras antologías publicadas a finales del siglo XX y primeros años del XXI por José Luis González, José Díaz, Clara Obligado y Raúl Brasca9 .

En el año 2002 aparecen los primeros microrrelatos de Merino agrupados en libro propio. Son los incluidos entre las cien piezas heterogéneas de Días imaginarios (2002). Y en 2005 se publican los Cuentos del libro de la noche, volumen formado casi exclusivamente por microrrelatos. Casi todos los microrrelatos de este libro (71, para ser precisos) están reunidos por el autor en la primera parte de La glorieta de los fugitivos. Minificción completa (2007), en donde también se recogen 22 microrrelatos procedentes de Días imaginarios, se añaden 18 más en el apartado de «Inéditos y dispersos» (si contamos como uno los Dos cuentos de navidad, que son complementarios), y una segunda parte, ya comentada, compuesta por «La glorieta miniatura (veinticinco pasos)», más un apéndice con «Diez cuentines congresistas». Con lo cual los 111 de la primera parte («ciento once fugitivos») más los 35 de la segunda suman un corpus total de 146 microtextos. Y así Merino se convertía, como anota F. Valls (2008: 311), en el «primer autor español que decide reunir sus piezas completas en un volumen», el primero de su género en ser galardonado con un premio tan importante como el Salambó, lo cual venía a reconocer su lugar de privilegio entre los cultivadores del microrrelato en España.

\footnotetext{
${ }^{8}$ Véase la antología preparada por Antonio Fernández Ferrer, La mano de la hormiga. Los cuentos más breves del mundo y de las literaturas hispánicas, Madrid, Fugaz, ediciones universitarias, 1990. En ella se publicaron La memoria confusa, Un regreso y Reunión conmemorativa. Tres historias de viajeros.

${ }^{9}$ Ecosistema se publicó en Dos veces cuento. Antología de microrrelatos, a cargo de José Luis González, Madrid, Ediciones Internacionales, 1998; también apareció en Ojos de aguja. Antología de microcuentos, preparada por José Díaz, Barcelona, Círculo de Lectores, 2000; y Ecosistema y Terapia fueron incluidos por Clara Obligado en Por favor, sea breve. Antología de relatos hiperbreves, Madrid, Páginas de Espuma, 2001. Y La memoria confusa, Lejanías y Cien fueron antologados por Raúl Brasca en Dos veces bueno. Cuentos breves de América y España, Buenos Aires, Ediciones del Instituto Movilizador de Fondos Cooperativos, 2002.
} 
Aunque, si miramos bien, por más que la compilación de Merino lleve el subtítulo de Minificción completa, no lo es en términos exactos, pues en La glorieta de los fugitivos se han eliminado 14 textos de los 85 que componen los Cuentos del libro de la noche, algunos, tal vez, por aproximarse a una extensión cercana a las cuatro páginas. Y también se ha prescindido de las ilustraciones que acompañaban a los textos en este libro y que con tanto acierto han comentado I. Andres-Suárez y Ángeles Encinar ${ }^{10}$, aquella con atención preferente a las imágenes tomadas de cuadros de otros artistas y manipuladas por Merino, esta más centrada en los dibujos y collages originales del autor. Dicha eliminación de ilustraciones puede, seguramente, obedecer a la convicción del autor según la cual el vehículo de la literatura es la palabra, por más que todos conozcamos la afición de Merino al dibujo (por ejemplo, en las dedicatorias de sus libros) y su destreza en la invención y manipulación de ilustraciones de todo tipo. Y a los microrrelatos incluidos en La glorieta de los fugitivos hay que añadir, para que la «minificción» sea completa, bastantes más intercalados después entre los cuentos de El libro de las horas contadas (2011); y la colección se completa, por ahora, con los quince microrrelatos incluidos junto con los cuentos de La trama oculta (2014).

Establecido ya el corpus meriniano de microrrelatos, voy a centrar la segunda parte de mi exposición en resaltar la importancia y frecuencia de algunos tipos de microrrelato entre los del autor leonés, analizando en el proceso aquellas piezas que, por su excelencia, resultan emblemáticas en su categoría. En su citado libro sobre El microrrelato. Teoría e historia D. Lagmanovich (2006: 123-138) destaca entre los tipos fundamentales de microrrelatos los que él llama de «reescritura y parodia». Son aquellos en los que se reelaboran textos y mitos clásicos, con audaces juegos de intertextualidad en las dos variedades y un componente humorístico en los de «parodia».

Entre los microrrelatos del gran lector que siempre ha sido Merino es frecuente la reescritura de textos clásicos con el fin de contarlos de otra manera, ya sea en son de homenaje a sus autores, ya como divertimento lúdico, ya con fines humorísticos mediante la parodia o la ironía, pero siempre con el afán de alumbrar algo nuevo en el experimento con el hipotexto aludido en el microrrelato final. Las mayores obras de la literatura universal ofrecen aquí el terreno apetecido para ser evocadas y

\footnotetext{
${ }^{10}$ Irene Andres-Suárez, «El universo iconotextual de José María Merino: Cuentos del libro de la noche», en I. Andres-Suárez y A. Rivas (eds.), La era de la brevedad. El microrrelato hispánico. (Actas del IV Congreso Internacional de Minificción), Palencia, Menoscuarto, 2008, págs. 371-396. Y Ángeles Encinar, «La visualización de las ficciones: Cuentos del libro de la noche, de José María Merino», en G. Champeau, J. F. Carcelén, G. Tyras y F. Valls (eds.), Nuevos derroteros de la narrativa española actual. Zaragoza, Prensas Unversitarias de Zaragoza, 2011, págs. 201-215.
} 
parcialmente reescritas con gran economía verbal, desde las Mil y una noches, con el relato de nuevas experiencias en el mundo de Sherezade (Golpe de estado), y la Biblia, con la reescritura de la expulsión del Paraíso (Génesis, 3), o la nueva vida del resucitado Lázaro (El final de Lázaro), hasta Augusto Monterroso y su célebre dinosaurio, pasando por una actualización paródica de la Odisea en La vuelta a casa, nuevas relaciones entre personajes de Shakespeare (La verdadera historia de Romeo y Julieta), ingeniosas invenciones cervantinas (en algunos microquijotes, que veremos después) e incluso de Velázquez, con una singular recreación de Las Meninas en Nicolasito.

Prestaré más atención a cuatro microrrelatos que brillan por su excelencia. En Génesis, 3 se reescribe el episodio bíblico en que Adán y Eva son expulsados del Paraíso. He aquí el texto de Merino (La glorieta..., 2007: 142):

Aquella mañana empezamos a ver las cosas más claras: la complejidad del universo, la evolución de los seres vivos, que sobre un punto de apoyo se podría levantar el planeta, que era la tierra la que giraba alrededor del sol y no al contrario y, sobre todo, intuimos que la existencia es un misterio indescifrable. No habían pasado ni dos horas cuando llegó el guardia con la carta de desahucio: el casero había conseguido echarnos a la calle. Nos vinimos a este lugar frío, tuvimos hijos. Del resto saben ustedes mucho más que nosotros. El caso es que aquella mañana, en el desayuno, habíamos compartido una manzana.

Notemos que con el hipotexto del episodio contado en el Génesis en la mente del lector, pues de todos es conocido, el autor ha concentrado en pocas líneas y con elipsis memorable, la fusión del mito bíblico y algunos hitos fundamentales en la historia de la humanidad, desde la expulsión del Paraíso, cuando Adán y Eva empiezan «a ver las cosas más claras», iniciando su conocimiento por haber mordido la manzana del árbol de la ciencia del bien y del mal, hasta la evolución de las especies (Darwin), pasando por la ley de la palanca formulada por Arquímedes y la teoría heliocéntrica de Galileo; pero tanta sabiduría no basta para comprender el «misterio indescifrable» de la existencia porque nadie ha logrado saberlo. La riqueza de este microrrelato se completa con la mención de la «carta de desahucio», tan desdichadamente actual, que los echa a la calle, el regusto de oralidad en el relato («Del resto saben ustedes mucho más que nosotros») y la mención final, como de pasada, del fruto prohibido, la «manzana», que está en el origen de todo.

Con El Quijote como hipotexto destacaré tres microrrelatos nacidos de la pasión lectora de Merino por Cervantes y de su maestría para pergeñar ingeniosas invenciones sobre el inmortal hidalgo-caballero manchego. En La cuarta salida ( $\mathrm{La}$ glorieta..., 2007: 101), que no necesita de comento, se cuenta que el profesor Souto 
José María Merino: teoría y práctica del microrrelato

ha descubierto en Alcaná de Toledo que el último capítulo del Quijote es una interpolación de un clérigo que, «por darle ejemplaridad a la novela», cambió el texto primitivo y su verdadero final. Pues hubo una cuarta salida de don Quijote:

... en ella encontró al mago que enredaba sus asuntos, un antiguo soldado manco al que ayudaba un morisco instruido, y consiguió derrotarlos. Así, los molinos volvieron a ser gigantes, las ventas castillos y los rebaños ejércitos, y él, tras incontables hazañas, casó con doña Dulcinea del Toboso y fundó un linaje de caballeros andantes que hasta la fecha han ayudado a salvar al mundo de los embaidores, follones, malandrines e hideputas que siguen pretendiendo imponernos su ominoso despotismo.

El segundo microquijote que quiero destacar es el número 24 de los «pasos» de La glorieta miniatura. Se titula Una mordedura y dice así:

Investigaba las especies del Jardín Literario: los ecos del cenador de los monólogos lo ensordecían, el rincón de las elegías le producía algo de alergia, solía ortigarse en la glorieta de los sonetos, en el sendero de la poesía de la experiencia daba demasiado el sol, a veces le sofocaba el intenso aroma de las novelas totales, le aburrían cómicamente los best sellers. Solía descansar en uno de los prados que rodean la Glorieta Miniatura, entre los relatos brevísimos, pero un día se quedó dormido y un minicuento carnívoro le mordió en un brazo. La mordedura se infectó, y quedó manco. Así fue como se le ocurrió escribir el Quijote más breve del mundo. (La glorieta..., 2007: 219).

Se nos presenta en este microrrelato a Cervantes como investigador de distintas formas y géneros literarios de su tiempo (monólogos, elegías, sonetos) y, tomándose todas las libertades, el autor extiende la exploración a corrientes y fenómenos literarios de otras épocas (novelas totales), incluso de la nuestra (poesía de la experiencia), aprovechando la ocasión para lanzar su crítica contra los best sellers. Y al final, tras descubrir el microrrelato y quedar infectado y «manco» por la mordedura de un «minicuento carnívoro», se sintió capaz de «escribir el Quijote más breve del mundo». En esta mordedura final se vislumbra el recuerdo de aquellas palabras en que Ana María Shua, uno de los maestros del género, pondera la fuerza expresiva de los microrrelatos: «Como las pirañas, son pequeños y feroces. Aconsejo descartarlos si no muerden» ${ }^{11}$.

Y este es «el Quijote más breve del mundo» nacido del fervor cervantino de Merino. Es el «paso» 25 de La glorieta miniatura. Se titula Historia de don Quijote y merece figurar -los tres citados de Merino lo merecen- entre los mejores micro-

\footnotetext{
${ }^{11}$ Tomo la cita de la antología de F. Valls Mar de pirañas, cit., pág. 7.
} 
quijotes reunidos por J. A. Epple (2005) porque en solo dos líneas encierra todo un tratado de exégesis de la gran novela cervantina. Dice así:

En un lugar de La Mancha vivió un ingenioso hidalgo y caballero que estuvo a punto de derrotar a la Realidad (La glorieta..., 2007: 220).

Y así llegamos a la original recreación meriniana del dinosaurio de A. Monterroso. En este complejo microrrelato, solo apto para lectores avisados, Merino lleva al extremo su actitud transgresora y su ludismo creador en la manipulación de los textos consagrados por la tradición. Pues, como explica I. Andres-Suárez (2007: 173), nuestro autor llega «al acto parricida de parodiar un texto considerado como modelo del propio microrrelato», El dinosaurio, de Monterroso, transformándolo, por medio de audaz metalepsis, en un sorprendente diálogo entre el escritor guatemalteco y el protagonista de La metamorfosis, de Kafka, tal vez con el ánimo de encumbrar al autor checo y hacerles compartir a los dos la paternidad del microrrelato como género narrativo. He aquí el microrrelato de Merino, que, con el título de Cien, cerraba el centenar de los textos incluidos en Días imaginarios:

$\mathrm{Al}$ despertar, Augusto Monterroso se había convertido en un dinosaurio. «Te noto mala cara», le dijo Gregorio Samsa, que también estaba en la cocina (La glorieta, 2007: 52).

Estos juegos en libertad creadora llevan a Merino a experimentar asimismo con microrrelatos donde lo metaliterario aparece, como en algunos de sus cuentos y novelas, impregnado de ludismo creativo y humor. Semejantes consideraciones metafictivas componen la sustancia reflexiva de microrrelatos como Cuento de primavera, con sus dos finales propuestos, y Huellas, donde la enumeración de objetos y señales en un sueño encuentra sentido en «Este relato». Otros experimentos buscan la hibridación, también como en sus novelas y cuentos, del microrrelato con el microensayo. Buenos ejemplos de este mestizaje los encontramos en muchos de los 25 «pasos» de La glorieta miniatura, ya comentados antes, y en el titulado Virus, híbrido de microrrelato-ensayo en la lección impartida por un profesor acerca de dichas invisibles y destructivas «entidades biológicas» para terminar denunciando el peligro encarnado por el ser humano para la supervivencia del planeta.

Otra categoría de microrrelatos muy importante entre los de Merino es la compuesta por los de naturaleza fantástica, que también constituye la veta principal de sus cuentos y novelas. Lo fantástico en Merino adopta múltiples motivos y variantes, desde figuraciones más allá de la muerte o su propia personificación hasta fantasías futuristas o la misteriosa existencia de mundos paralelos al nuestro, pasando por fi- 
guras tradicionales de fantasmas, vampiros y seres invisibles, y por la confrontación entre el yo y su doble o la nebulosa frontera entre vigilia y sueño, ficción y realidad. Pero las fantasías del autor leonés parten siempre de la realidad, de sus pliegues ocultos e incluso de problemas cotidianos, con el fin de iluminar el mundo real y sus extrañezas y misterios desde otros ángulos más abiertos, con plena libertad y sin las limitaciones impuestas por la razón.

Destacaré dos microrrelatos, entre otros dignos de mención, como textos más representativos de lo fantástico en Merino. El primero, construido en segunda persona autorreflexiva, lleva por título, muy esclarecedor, Después del accidente:

No sientes el silencio de la noche porque dentro de ti continúan vibrando todos los sonidos del accidente, el chirrido del frenazo, el golpe contra la barrera, el retumbar del vehículo al despeñarse. Y escuchas el murmullo de la radio, una voz ininteligible, mientras la luz cada vez más débil de los faros hace brillar la escarcha en los matorrales. Hay también otros brillos y, desde el lugar que ocupa tu cuerpo, caído fuera del coche, comprendes de repente que son los reflejos de esa iluminación escasa en unos ojos. «iLaura!», exclamas aterrorizado, incorporándote. Entonces los ves. Sobre sus uniformes reluce la fosforescencia de unos cascos que parecen enormes y extraños en la negrura. «No te preocupes por ella», dice el más alto, con voz serena, «eres tú quien debe venir con nosotros. Ella está viva» (La glorieta..., 2007: 29).

La sobriedad, precisión y concentración expresiva en la certera enumeración realista de impresiones y sensaciones parecen insuperables. En contraste con el desconcierto y la inquietud que se imponen al final, encarnados en las misteriosas figuras de esos seres con «unos cascos que parecen enormes y extraños en la negrura». ¿Quiénes pueden ser? Según conjeturas de I. Andres-Suárez (2007: 162), «¿son policías de tráfico que llegan a prestarle auxilio tras el accidente, o unos ángeles o demonios dispuestos a conducirlo a su último destino? La irresoluble incertidumbre se mantiene intacta».

Microrrelatos de naturaleza fantástica son también Página primera, El castillo secreto, Metamorfosis, Comparsas, Posdata, Poca luz, entre otros muchos escritos por este autor, considerado como uno de los maestros de la narrativa fantástica en nuestro tiempo. De todos ellos quiero destacar los tres de la serie «Despistados», cuyos narradores y protagonistas parecen quedar atrapados en angustiosos sueños o pesadillas de donde no pueden salir para volver a la vigilia porque, realmente, están muertos, aunque ellos no lo saben. El más logrado de la serie es el Despistado (tres): 
Me acosté y me quedé dormido enseguida, pero he despertado de repente sintiendo el agobio de mi propio lecho, que ha dejado de ser blando y que oprime mis codos y mis costados con rara pero insoslayable rigidez. En la negrura del dormitorio me parece escuchar murmullos, voces que cuchichean o rezan. Intento moverme, levantarme, pero no lo consigo e imagino que estoy atrapado en el umbral de un sueño. Paciencia. ( $L a$ glorieta..., 2007: 141).

La «paciencia» tendrá que ser eterna, pues las impresiones y sensaciones realistas propiciadas por ese lecho duro, angosto y rígido en «la negrura del dormitorio» donde le parece escuchar «murmullos, voces que cuchichean o rezan», más la imposibilidad de moverse, no dejan lugar a dudas entre el sueño y la muerte. Además la ilustración del microrrelato lo explicitaba con claridad en el féretro sostenido por dos esqueletos tomada de un fragmento manipulado del óleo El triunfo de la muerte, de Pieter Brueghel, el Viejo. Y, como advierte Á. Encinar (2011: 211), en el conjunto ficticio y visual de este tríptico de la muerte «Merino transmite al lector un estado de desasosiego in crescendo, paliado de forma magistral por el humor que supone estigmatizar a su protagonista de despistado, para cuestionar no solo la existencia de otra posible realidad en la muerte sino también la inquietante dificultad de reconocerse en esa situación».

El humor es otro componente destacado en los microrrelatos de Merino como en ningún otro lugar de su obra. Se manifiesta de diferentes maneras: por vía del absurdo, como en La gran catarata, donde algo tan banal como un inoportuno lápiz incrustado en la ranura de un asiento de la avioneta impide al obsesionado protagonista atender a lo fundamental y admirar el impresionante salto de agua porque ha perdido el tiempo en lo secundario, empeñado en extraer el lapicero; mediante la parodia y la ironía, implicadas en la crítica social y del mundo literario, como en Best-Sellers o en Crisis de percepción; y también asociado a reflexiones metaliterarias, como en Genética y en Final infeliz, entre otros «cuentines congresistas». Y coincido con F. Valls (2008: 173) en resaltar que el microrrelato con mayores dosis de humor es Satánica, donde el diablo, more unamuniano, planta cara al autor para quejarse, con la voz gangosa de Marlon Brando en El Padrino, de que en «un libro de la noche» no se le haya hecho el menor caso, para acabar cautivo y congelado en el frigorífico después de haber sido amasado por la esposa del autor en una bola metida en una bolsa de plástico.

El final de Satánica pone de relieve uno de los problemas que más inquietan a Merino como persona comprometida, solidaria y preocupada por el presente y futuro de la humanidad, al advertir que, con Satanás cautivo, «tal vez en el libro de la noche ya no fructifiquen la iniquidad, la injusticia ni el crimen, pero en el libro del 
día ese cautiverio del Señor del Mal no se ha notado, el mundo sigue dominado por la hipocresía, la guerra, el horror. Y me da miedo imaginar a quién corresponde el señorío del libro del día» (La glorieta..., 2007: 147). Con ello vamos cerrando este recorrido por los microrrelatos de Merino llamando la atención sobre otro de sus aspectos temáticos más importantes: el referido a su preocupación por algunos peligros que amenazan nuestro mundo, desde el frágil equilibrio entre el ser humano y la naturaleza (La hormiga en el asfalto) hasta los horrores de la guerra, que no perdona ni a los Reyes Magos (Dos cuentos de navidad), pasando por la locura depredadora de los hombres (Virus), sin que tampoco aquí falte la correspondiente parodia humorística $(M o s c a)$.

Como antes he indicado, en El libro de las horas contadas Merino incluyó bastantes microrrelatos más, distribuidos en artístico maridaje con los cuentos. Son, exactamente, 17 cuentos y 55 microrrelatos, estos agrupados en 6 series, más algunos intercalados en el texto de los cuentos (por ejemplo, los tres incluidos en el relato Zambulianos, en el capítulo 5). Con este libro Merino profundiza con acierto en experimentos narrativos alentados por el afán de renovación de los géneros tradicionales en favor del mestizaje mediante la hibridación de sus componentes formales e incluso la composición por medio de una sucesión encadenada de cuentos y microrrelatos con marco engarzados por múltiples elementos comunes que aproximan el conjunto a una leve trama novelesca.

El libro de las horas contadas es una creación genuina del mejor Merino, maestro en la manipulación del arte de contar historias en la línea de imposible separación entre ficción y realidad. Con razón F. Valls destacaba en su reseña (Turia: 2012) que en este afortunado experimento «muestra Merino, en síntesis, los impulsos de su imaginación, sus obsesiones narrativas, por medio de diversos géneros, estéticas, procedimientos, motivos o personajes». Porque no se trata solo de un gran libro de cuentos y de microrrelatos, sino, sobre todo, de un gran libro de cuentos y microrrelatos integrados en una unidad artística superior, una especie de «novela híbrida» que Valls propone llamar «un ciclo de narrativa breve, que podría ser mixtura [...] entre el cada vez más frecuente ciclo de cuentos y el todavía poco habitual ciclo de microrrelatos».

Los elementos comunes que anudan estructuralmente las historias contadas en este proteico libro son la presencia dominante de tres personajes: dos unidos en matrimonio, Pedro y Mónica; y el tercero, Fran, amigo de ellos desde sus estudios universitarios. Pedro vive días de incertidumbre a causa de su enfermedad, entre dos operaciones, sometido a una fuerte medicación (de ahí el título del libro), y escribe ficciones, que Mónica lee y comenta en varios momentos. La variedad de los cuentos y microrrelatos resulta unificada por estrechos lazos compositivos en múltiples recu- 
rrencias como el predominio espacial de la casa de campo de los abuelos de Pedro, el chalé de la urbanización donde vive el matrimonio, la hipótesis del engaño sugerida por Pedro en su ficción sobre la secreta relación entre su mujer y su mejor amigo, y que ellos no entienden por confundir ficción y realidad (todo ello asociado a la visión de un meteorito, en el primer cuento, que es el embrión de todo el libro), la invención de seres extraterrestres llamados zambulianos y la mala salud de Pedro, con su desasosiego y su medicación que naturalizan los sueños y fantasías de sus invenciones.

En los cuentos y microrrelatos que componen los 23 capítulos del libro se abordan los temas característicos de Merino, como el poso indeleble de los recuerdos de infancia y juventud, el paso del tiempo, la huella de los mitos, la ciencia ficción, las ensoñaciones y fantasías nacidas en misteriosos pliegues de la vida cotidiana, el imperceptible deslizamiento entre lo real y lo imaginado, y la defensa de la función de la ficción en la vida. Este abanico de temas recibe su tratamiento literario en relatos de muy variada índole. Dicha variedad empieza por la extensión nunca larga de los cuentos, entre los cuales se distribuyen simétricamente seis series de microrrelatos, que componen otros tantos capítulos, con numerosos ejemplos de excelencia entre unos y otros. La diversidad se extiende asimismo a la naturaleza de los cuentos y microrrelatos, pues aun predominando la combinación entre los de carácter fantástico y realista, rasgos a menudo integrados en el mismo texto, hay relatos concebidos como fábulas (La pena del mundo), historias de ciencia ficción (Zambulianos), cuentos que funcionan como metaficciones en sí mismos y en su relación con otros (La telaraña), microrrelatos que juegan con las coordenadas anunciadas en el conglomerado verbal de su epígrafe «Espaciosueñotiempo», otros que constituyen esbozos de nuevas posibilidades narrativas en las relaciones entre Pedro, Mónica y Fran (Siete novelas al minuto) y alguno que se acerca mucho a la greguería (De libros y de rosas).

Por todo ello El libro de las horas contadas encierra una fiesta literaria de extraordinaria riqueza en su inteligente juego con la ficción y la realidad en unas invenciones nacidas de lo vivido por Mónica y lo imaginado por Pedro en su entrega a la escritura contra el tiempo destructor. Su fervorosa defensa de la ficción y sus leyes propias, con significativos homenajes a los maestros del cuento y el microrrelato (Andersen, Maupassant, Poe, Chéjov, Monterroso...), cristaliza en relatos y microrrelatos del más alto mérito literario magistralmente integrados en esta unidad artística superior.

Y terminamos con una breve referencia a La trama oculta (cuentos de los dos lados con una silva mínima), donde Merino ha reunido 20 cuentos y 15 microrrelatos (17 si contamos los dos brevísimos del comienzo) que ilustran sus diversas maneras de concebir y practicar estas dos modalidades de la narración corta. En los microrrelatos, que componen la tercera parte del libro, Silva mínima, Merino renue- 
va su tratamiento de temas, motivos y obsesiones recurrentes, desde incursiones en lo fantástico hasta la reescritura de episodios de obras muy conocidas, pasando por el doble, el sueño y la muerte. Y también aquí hay microrrelatos antológicos, como Convivencia, Habitación 201, Cenizas, El fantasma, La poza en el atardecer, Horóscopo, Autoficción y Origen nonato, entre otros modelos de intensa concentración y narratividad en busca de la sugerencia y el quiebro final.

\section{Conclusiones}

Es hora de rematar con algunas conclusiones inferidas de cuanto llevamos dicho. Creo que a la destreza narrativa de Merino le van como de molde las características del microrrelato porque ha encontrado en este género la mesa de trucos que su obrador necesitaba para explotar al máximo su ludismo creador a partir de sus muchas lecturas y de sus invenciones fantásticas. En sus microrrelatos hay una perfecta adecuación entre las realizaciones prácticas y las ideas expuestas por él en sus reflexiones teóricas. Rasgo fundamental de muchos microtextos merinianos es la continua voluntad de experimentación, ya en asociaciones insólitas, ya en audaces juegos de intertextualidad con grandes obras literarias del pasado. Esta actitud lúdica se vuelve a menudo transgresora frente a la tradición cultural, y subversiva frente a lo establecido en el presente. En el microrrelato encontró Merino el cauce privilegiado para desplegar el humor, como nunca había aflorado antes en sus narraciones. Y en los que lleva escritos ha tratado los mismos temas que en el resto de su obra narrativa, desde mitos y leyendas de siempre o el recuerdo imborrable de ciertas lecturas hasta su preocupación por la naturaleza y el destino de la humanidad, pasando por la historia y lo fantástico en sus múltiples manifestaciones.

\section{Bibliografía citada}

Andres-Suárez, Irene, «La estética de la brevedad. Tres clásicos del microrrelato: L. M. Díez, J. Ma Merino y J. P. Aparicio», Siglo XXI. Literatura y cultura españolas, Revista Anual de la Cátedra Miguel Delibes, núm. 5, Universidad de Valladolid, 2007, págs. 153-175.

Andres-Suárez, Irene, El microrrelato español. Una estética de la elipsis, Palencia, Menoscuarto, 2010.

Andres-Suárez, Irene, Antología del microrrelato español (1906-2011). El cuarto género narrativo, Madrid, Cátedra, 2012.

Andres-Suárez, Irene, El microrrelato en la España plurilingüe, Valladolid, Universidad de Valladolid, 2018. 
Andres-Suárez, Irene, y Rivas, Antonio (eds.), La era de la brevedad. El microrrelato hispánico, Palencia, Menoscuarto, 2008.

Brasca, Raúl, Dos veces bueno. Cuentos breves de América y España, Buenos Aires, Ediciones del Instituto Movilizador de Fondos Cooperativos, 2002.

Díaz, José, Ojos de aguja. Antología de microcuentos, Barcelona, Círculo de Lectores, 2000.

Encinar, Ángeles, «La visualización de las ficciones: Cuentos del libro de la noche, de José María Merino», en Champeau, G., Carcelén, J. F., Tyras, G., y Valls, F. (eds.), Nuevos derroteros de la narrativa española actual, Zaragoza, Prensas Universitarias de Zaragoza, 2011.

Encinar, Ángeles, y Valcárcel, Carmen, Más por menos, Madrid, Sial, 2011.

Fernández Ferrer, Antonio, La mano de la hormiga. Los cuentos más breves del mundo y de las literaturas hispánicas, Madrid, Fugaz, 1990.

Epple, Juan Armando, MicroQuijotes, Barcelona, Thule, 2005.

González, José Luis, Dos veces cuento. Antología de microrrelatos, Madrid, Ediciones Internacionales, 1998.

Lagmanovich, David, La otra mirada. Antología del microrrelato hispánico, Palencia, Menoscuarto, 2005.

Lagmanovich, David, El microrrelato. Teoría e historia, Palencia, Menoscuarto, 2006.

Merino, José Ma , Días imaginarios, Barcelona, Seix Barral, 2002.

Merino, José M ${ }^{\mathrm{a}}$, Ficción continua, Barcelona, Seix Barral, 2004.

Merino, José $\mathrm{M}^{\mathrm{a}}$, Cuentos del libro de la noche, Madrid, Alfaguara, 2005.

Merino, José $\mathrm{M}^{\mathrm{a}}$, «El microrrelato. Teoría e historia», Revista de Libros, núm. 129, Madrid, septiembre de 2007.

Merino, José $\mathrm{M}^{\mathrm{a}}$, «Diez cuentos brevísimos, con unas gotas de teoría», en Teresa Gómez Trueba (ed.), Mundos mínimos. El microrrelato en la literatura española contemporánea, Gijón, Cátedra Miguel Delibes-Libros del Pexe, 2007, págs. 183192.

Merino, José $\mathrm{M}^{\mathrm{a}}$, en La glorieta de los fugitivos Minificción completa, Madrid, Páginas de Espuma, 2007.

Merino, José Ma , El libro de las horas contadas, Madrid, Alfaguara, 2011.

Merino, José $\mathrm{M}^{\mathrm{a}}$, La trama oculta (cuentos de los dos lados con una silva mínima), Madrid, Páginas de Espuma, 2014.

Obligado, Clara, Por favor, sea breve. Antología de relatos hiperbreves, Madrid, Páginas de Espuma, 2001.

Valls, Fernando, Soplando vidrio y otros estudios sobre el microrrelato español, Madrid, Páginas de Espuma, 2008. 
Valls, Fernando, Mar de pirañas. Nuevas voces del microrrelato español, Palencia Menoscuarto, 2012.

Valls, Fernando, «Sobre El libro de las horas contadas, de José María Merino», Turia, núms. 101-102, Teruel, marzo-mayo de 2012.

Valls, Fernando, «El microrrelato como género literario», en Ottmar Ette, Dieter Ingenschay, Friedhelm Schmidt-Velle, Fernando Valls (eds.), MicroBerlín. De minificciones y microrrelatos, Madrid, Iberoamericana-Vervuert, 2015, págs. 21-49. 